\title{
Clinical Features and Treatment Outcomes of Hematopoietic Stem Cell Transplan- tation During 2006-2016 at a Single Institution in Miyazaki Prefecture
}

\author{
Noriaki Kawano $^{1 *}$, Shuro Yoshida ${ }^{*}$, Hidemi Shimonodan ${ }^{2 *}$, Takuro Kuriyama ${ }^{1}$, Nobuyuki Ono ${ }^{1}$, Daisuke Himeji ${ }^{1}$ \\ Taro Tochigi ${ }^{1}$, Takashi Nakaike ${ }^{1}$, Tomonori Shimokawa ${ }^{1}$, Shingo Urata ${ }^{1}$, Kiyoshi Yamashita ${ }^{1}$, Masaki Ito ${ }^{3}$, \\ Hideki Koketsu ${ }^{4}$, Atsushi Toyofuku ${ }^{5}$, Takahiro Muranaka ${ }^{6}$, Kousuke Marutsuka ${ }^{7}$, Koichi Mashiba ${ }^{1}$, Ikuo Kikuchi ${ }^{1}$, \\ Shigeyoshi Makino ${ }^{8}$, Hidenobu Ochiai ${ }^{9}$, Kazuya Shimoda ${ }^{10}$, Koji Nagafuji ${ }^{11}$, Yasuo Mori ${ }^{12}$, Toshihiro Miyamoto ${ }^{12}$, \\ Koichi Akashi ${ }^{12}$ \\ ${ }^{1}$ Department of Internal Medicine/Hematology, Miyazaki Prefectural Miyazaki Hospital \\ ${ }^{2}$ Department of Pediatrics, Miyazaki Prefectural Miyazaki Hospital \\ ${ }^{3}$ Department of Oral and Maxillofacial Surgery, Miyazaki Prefectural Miyazaki Hospital \\ ${ }^{4}$ Department of Dermatology, Miyazaki Prefectural Miyazaki Hospital \\ ${ }^{5}$ Department of Surgery, Miyazaki Prefectural Miyazaki Hospital \\ ${ }^{6}$ Department of Radiology, Miyazaki Prefectural Miyazaki Hospital \\ ${ }^{7}$ Department of Pathology, Miyazaki Prefectural Miyazaki Hospital \\ ${ }^{8}$ Department of Transfusion Medicine, Toranomon Hospital \\ ${ }^{9}$ Trauma and Critical Care Center, Faculty of Medicine, University of Miyazaki \\ ${ }^{10}$ Division of Gastroenterology and Hematology, Department of Internal Medicine, Faculty of Medicine, University of \\ Miyazaki \\ ${ }^{11}$ Division of Hematology and Oncology, Department of Medicine, Kurume University School of Medicine, Kurume, \\ Japan \\ ${ }^{12}$ Department of Medicine and Biosystemic Science, Graduate School of Medical Sciences, Kyushu University
}

Background: The elucidation of clinical characteristics in deceased patients is essential to improve outcomes of hematopoietic stem cell transplantation (HSCT) for refractory/relapsed hematological malignancy. Patients and Methods: We retrospectively examined 81 refractory/relapsed hematological malignancy patients treated with allogeneic HSCT (allo-HSCT) (54) and autologous HSCT (auto-HSCT) (27) in our hospital from 2006 to 2016. Results: Consistent with previous Japan Marrow Donor Program annual reports, the overall survival (OS) rate of allo-HSCT and auto-HSCT patients were $59 \%$ and $84 \%$ at five years, respectively. Among patients receiving alloHSCT, severe regimen-related toxicity (RRT) (grade $\geq 3$ ) events included cardiomyopathy due to cyclophosphamide (1), idiopathic pulmonary syndrome (1), acute graft-versus-host disease (GVHD) III-N (3), acute-exacerbated chronic GVHD (2), engraftment failure (2), human herpesvirus-6 encephalitis (2), and fungal infection (7). Moreover, univariate analysis identified disease risk index (DRI) and non-CR status before allo-HSCT as prognostic factors of OS. Among patients receiving auto-HSCT, the severe RRT event was thrombotic microangiopathy (1). The relapse after auto-HSCT in three patients with malignant lymphoma was a serious concern. Conclusion: Our study revealed critical issues in non-CR patients and those with high/very high DRI before allo-HSCT. Furthermore, the occurrence of severe RRT indicated the need for improvements in allo- and auto-HSCT.

(Journal of Hematopoietic Cell Transplantation $8(4)$ : 122-134, 2019.)

Submitted November 30, 2018; Accepted June 7, 2019; Published online, October 15, 2019. (Handling Editor: Tetsuya Nishida, Nagoya University Hospital)

Key words: auto-HSCT, allo-HSCT, RRT, non-CR, disease risk index

Correspondence: Noriaki Kawano, Department of Internal Medicine, Miyazaki Prefectural Miyazaki Hospital, 5-30 Kitatakamatsu, Miyazaki, 880-8510, Japan. E-mail: kawanoriaki@yahoo.co.jp

* These authors are co-first and contributed equally to this work.

dx.doi.org/10.7889/hct-18-022 (C) The Japan Society for Hematopoietic Cell Transplantation. 


\section{Introduction}

Hematopoietic stem cell transplantation (HSCT), including allogeneic HSCT (allo-HSCT) and autologous HSCT (autoHSCT), is performed to treat patients with refractory or relapsed hematological malignancy and hematological disorders. ${ }^{1-6}$ In recent decades, progress and advancements in alloHSCT strategies such as the donor source, graft-versus-hostdisease (GVHD) prophylaxis, conditioning regimen, infection control, and regimen-related toxicity (RRT) in allo-HSCT have rapidly changed and expanded the application of alloHSCT in clinical practice. ${ }^{1-6}$ However, the adverse effects of allo-HSCT including RRT, acute and chronic GVHD, bacterial/fungal/viral infection and sinusoidal obstruction syndrome/veno-occlusive disease (SOS/VOD), and relapse of the refractory or relapsed hematological malignancy and hematological disorder remain life-threatening challenges in clinical practice. ${ }^{1-6}$ Thus, it is essential to elucidate the clinical characteristics of HSCT, including allo-HSCT and autoHSCT, for refractory/relapsed hematological malignancy and hematological disorder to improve treatment outcomes and reduce the associated adverse effects in clinical practice.

Herein, we retrospectively studied 81 patients with refractory/relapsed hematological malignancy treated with alloHSCT (54 cases) and auto-HSCT (27 cases) in our hospital from 2006 to 2016 . This retrospective study assessed the present status of the clinical features and treatment outcomes and identified several critical points that require improvement in clinical practice.

\section{Patients and Methods}

We retrospectively analyzed the clinical features and treatment outcomes of patients who underwent HSCT, including 54 and 27 who received allo-HSCT and auto-HSCT, respectively, during an 11-year period from January 2006 to December 2016

The indications for auto-HSCT or allo-HSCT were based on the guidelines from the Japan Society of Hematopoietic Cell Transplantation (JSHCT), the Japanese Society of Hematology (JSH), and the Fukuoka Bone Marrow Transplantation Group (FBMTG) . ${ }^{7}$ Patient comorbidities were scored according to Hematopoietic Cell Transplantation (HCT)-specific Comorbidity Index (HCT-CI) scores of $<2$.

Based on the allo-HSCT treatment guidelines by the FBMTG,${ }^{7}$ the indications for allo-HSCT are as follows: age
$<65$ years; Eastern Cooperative Oncology Group performance status (PS) score of 0-2; adequate liver and kidney function; serum bilirubin, $<2.0 \mathrm{mg} / \mathrm{dL}$; and serum creatinine level of $<2.0 \mathrm{mg} / \mathrm{dL}$. Patients $<55$ years of age were preconditioned with a myeloablative conditioning regimen (MAC) consisting of total body irradiation (TBI) of 12 Gray (Gy) and cyclophosphamide administration (CPA; $120 \mathrm{mg} / \mathrm{kg}$ ), whereas patients aged between 55 and 65 years were preconditioned with a reduced-intensity conditioning regimen (RIC) according to the JSHCT guidelines, consisting of fludarabine (Flu; $\left.180 \mathrm{mg} / \mathrm{m}^{2}\right)$, busulfan (BU; $6.4 \mathrm{mg} / \mathrm{kg}$ ), and low-dose TBI (2 Gy), for myeloid malignancy ${ }^{8}$ and Flu $\left(125 \mathrm{mg} / \mathrm{m}^{2}\right)$, melphalan (L-PAM; $140 \mathrm{mg} / \mathrm{m}^{2}$ ), and low-dose TBI (2 Gy) for lymphoid malignancy. ${ }^{9}$ Patients with poor disease control before allo-HSCT additionally received high-dose cytarabine (HDAC) or etoposide (VP-16) during the lymphoid malignancy conditioning regimen. ${ }^{5}$ Eligible donors included sibling donors, unrelated donors from the Japan Marrow Donation Program (JMDP) and cord blood (CB) donors from the Japan Cord Blood Bank Network (JCBBN). GVHD prophylaxis was done by the administration of short-term methotrexate (MTX) plus cyclosporine (CSP) in sibling donors and CB donors for allo-HSCT and the administration of shortterm MTX plus tacrolimus (FK 506) in UR-BM donors for allo-HSCT, respectively. Furthermore, in haploidentical donors for allo-HSCT, GVHD prophylaxis was done by the administration of tacrolimus, mycophenolate mofetil (MMF) plus post-transplant cyclophosphamide $(40 \mathrm{mg} / \mathrm{kg} /$ day on days 3 and 4) with the conditioning regimen consisted of Flu $\left(150 \mathrm{mg} / \mathrm{m}^{2}\right)$, BU $(6.4 \mathrm{mg} / \mathrm{kg})$, and TBI (4 Gy). ${ }^{10}$ We previously reported on nine patients with aggressive-type adult T-cell lymphoma (ATL) who underwent allo-HSCT at a single institution in Miyazaki prefecture between January 2006 and December 2016. ${ }^{11}$

For auto-HSCT, the conditioning regimens consisted of granulocyte colony-stimulating factor (G-CSF) plus busulfan, etoposide, and cytarabine (BEA) for acute myeloid leukemia (AML), ranimustine (MCNU), carboplatin, etoposide, and cyclophosphamide (MCVC) for malignant lymphoma (ML), and L-PAM for multiple myeloma (MM) and Waldenström macroglobulinemia (WM). Peripheral blood stem cell harvest (PBSCH) was performed during chemotherapy by HDAC for AML, VP-16 for ML, and high-dose cyclophosphamide (HDCY) for MM and WM.

Based on a previous FBMTG study ${ }^{7}$ and the International Working Group (2003) ${ }^{12}$ guidelines for hematological malig- 


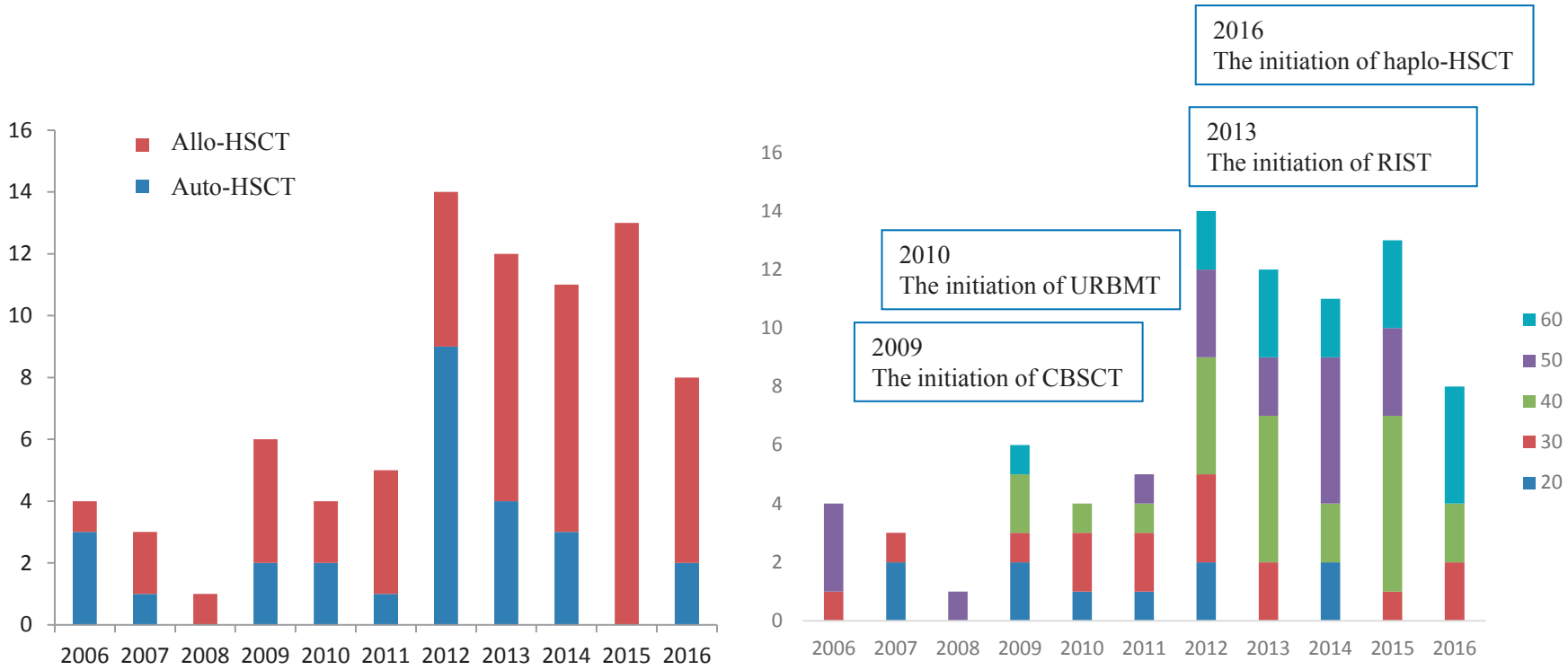

Figure 1. Transition of allo-HSCT and auto-HSCT from January 2006 to December 2016

nancy, a complete remission $(\mathrm{CR})$ was defined as $<5 \%$ blasts in the bone marrow and disappearance of all tumor for at least four weeks. Non-CR was defined as $>5 \%$ blasts in the bone marrow for at least four weeks. For malignant lymphoma, a partial response (PR) was defined as $\mathrm{a} \geq 50 \%$ reduction in tumor size.

Adverse events (AEs) were evaluated using the National Cancer Institute Common Terminology Criteria for AEs (CTCAE-JCOG), versions 3.0, 4.0, version 5.0. Severe RRT was defined as grade $\geq 3$. Positive findings for cytomegalovirus (CMV) antigenemia were defined as low- and intermediate-risk $(\geq 10$ positive cells/50,000 WBC) or high-risk $(\geq$ 2 positive cells $/ 50,000 \mathrm{WBC}$ ) according to the JSHCT guidelines for CMV infection.

The Kaplan-Meier method was used to estimate the probabilities of OS after the initiation of treatment with allo-HSCT or auto-HSCT. OS was defined as the time from the first day of allo-HSCT or auto-HSCT administration to the day of death or that of the last follow-up. The statistical significance of differences in survival was determined using log-rank tests. Moreover, among various factors such as disease status at transplant (CR vs. non-CR), conditioning regimen (MAC vs. RIC), type of donor source, and disease risk index (DRI), ${ }^{13}$ we performed univariate analysis to identify those affecting the OS. The cumulative incidence was estimated for engraftment (neutrophils), acute GVHD, and chronic GVHD. Statistical significance was determined using a two-sided $P$-value $(<0.05)$.

This retrospective study was conducted in compliance with the guidelines for good clinical practice and the ethical principles of the Declaration of Helsinki. The appropriate ethics committees and institutional review boards approved this study.

\section{Results}

Patient characteristics and treatment outcomes of alloHSCT

The transition of allo-HSCT from January 2006 to December 2016 is shown in Figure 1. The number of patients treated with allo-HSCT gradually increased due to the initiation of cord blood stem cell transplantation (CBSCT) in 2009, UR-BM transplantation from the JMDP in 2010, reducedintensity hematopoietic stem cell transplantation (RIST) in 2013, and haplo-HSCT in 2016. Notably, the number of patients aged 60 years increased with the initiation of RIST in 2013.

The patient characteristics are described in Table 1A. The total of 54 patients included 31 male and 23 female patients. The median age was 46 years (20-69).

The etiologies of patients with hematological malignancy and those without are described in Table 1A. Allo-HSCT was performed in 54 patients with acute myeloid leukemia (AML) (18 patients), adult T-cell leukemia/lymphoma (ATL) (10 patients), acute lymphocytic leukemia (ALL) (eight patients), malignant lymphoma (ML) (eight patients), myelodysplastic syndrome (MDS) (six patients), aplastic anemia (AA) (two patients), hemophagocytic lymphohistiocytosis (HLH) (one 
Table 1A. Characteristics of the 54 allo-HSCT patients

\begin{tabular}{|c|c|}
\hline & Clinical characteristics \\
\hline Sex & Male 31, Female 23 \\
\hline Underlying diseases & $\begin{array}{l}\text { AML (18), ATL (10), ALL (8), ML (8), MDS (6), AA (2), HLH (1), CML (1) } \\
\text { (Furthermore, retransplantation was performed for two patients }(\mathrm{CML} \text { and } \mathrm{AML} \text { ) with engraft- } \\
\text { ment failure (EF) after allo-HSCT, and two relapsed AML patients after allo-HSCT, respec- } \\
\text { tively) }\end{array}$ \\
\hline Donor sources & $\begin{array}{l}\text { sibling donors: BM (5), sibling donors: PB (12), UR-BMT donors from JMPD (25) and CB } \\
\text { (12) }\end{array}$ \\
\hline $\begin{array}{l}\text { Number of HLA mismatch between recipi- } \\
\text { ent and donor }\end{array}$ & $\begin{array}{l}\text { HLA full matched donor: } 37 \text {, HLA-DR } 1 \text { locus mismatched donor: 2, HLA-2 locus mis- } \\
\text { matched donor: } 12 \text {, haploidentical donor: } 3\end{array}$ \\
\hline Conditioning & First transplantation (MAC: 35, RIC 19), second transplantation（RIC: 4) \\
\hline Disease status before allo-HSCT & $\mathrm{CR}(22), \mathrm{PR}(5)$ and non-CR (27) \\
\hline Disease risk index (DRI) & Low: 4, Intermediate: 20 , High: 20 , Very high: 8 . Others: 2 (AA) \\
\hline The number of allo-HSCT (first or second) & Fisrt transplantation: 54, Second transplantation: 4 (EF: 2, relapse: 2) \\
\hline CMV serology & CMV-lgG+: 54, All 54 patients had prior infection with CMV \\
\hline $\begin{array}{l}\text { Cumulative incidence of neutrophil engraft- } \\
\text { ment }\end{array}$ & $\begin{array}{l}\text { The median time of engraftment in allo-HSCT was day } 20 \text { (14-24). The cumulative inci- } \\
\text { dence of engraftment (neutrophil) at } 30 \text { days in allo-HSCT was } 0.963(0.8557-0.990)\end{array}$ \\
\hline $\begin{array}{l}\text { Cumulative incidence of acute GVHD/ } \\
\text { chronic GVHD }\end{array}$ & $\begin{array}{l}\text { The cumulative incidence of acute GVHD was } 0.3148(0.179-0.4281) \text { at day } 100 \text {. The } \\
\text { grade } 1,2,3 \text { and } 4 \text { of acute GVHD was } 3,11,2 \text { and } 1 \text {, respectively. The cumulative inci- } \\
\text { dence of chronic GVHD } 0.1667(0.061-0.2604) \text { at } 1 \text { year }\end{array}$ \\
\hline Severe RRT (grade $\geq 3$ by CTCAE-JCOG) & $\begin{array}{l}\text { The severe } 20 \text { RRT cases such as cardiomyopathy due to CPA ( } 1 \text { ), IPS ( } 1 \text { ), acute GVHD: } \\
\text { II-IV ( } 3 \text { cases: } 5 \% \text { ), chronic GVHD ( } 2 \text { ): lung ( } 1 \text { ), myelitits ( } 1 \text { ), Engraft failure ( } 2 \text { ), HHV-6 } \\
\text { encephalititis (5), EBV-LPD ( } 1 \text { ), fungal infection ( } 7 \text { ), CMV colitis ( } 2 \text { ), subcutaneous } \\
\text { emphysema - mediastinal emphysema (1) }\end{array}$ \\
\hline Infection (Fungal infection, viral infection) & $\begin{array}{l}\text { Fungal infection: Asperugillus pneumonia (6), Mucor pneumonia (1) } \\
\text { Viral infection: HHV-6 infection (8): CBSCT (6) and re-transplantation (2), BK viral infec- } \\
\text { tion (3), ADV infection (1). EBV-LPD (1) }\end{array}$ \\
\hline OS & OS at 5 years: $0.594(0.441-0.719)$ with median OS of 290 days (19-3410) \\
\hline Relapse & 18 cases were relapsed among 54 allo-HSCT patients \\
\hline
\end{tabular}

AML, acute myeloid leukemia; ATL, adult T-cell leukemia/lymphoma; ALL, acute lymphoblastic leukemia; ML, malignalt lymphoma; MDS, myelodysplastic syndrome; AA, aplastic anemia; $\mathrm{HLH}$, hemophagocytic lymphohistiocytosis; CML, chronic myeloid leukemia; EF, engraftment failure; BM, bone marrow; PB, peripheral blood stem cell; $\mathrm{CB}$, cord blood; MAC, myeloablative conditioning regimen; RIC, reduced intensity conditioning regimen; CR, complete response; PR, partial response; RRT, regimen related toxicity; IPS, idiopathic pneumonia syndrome; HHV-6, human herpes virus-6; EBV-LPD, Epstein-Barr virus-associated lymphoproliferative disorders; OS, overall survival.

Table 1B. Characteristics of the 27 auto-HSCT patients

\begin{tabular}{|c|c|}
\hline & Clinical characteristics \\
\hline Sex & $\begin{array}{l}\text { Male: } 13 \\
\text { Female: } 14\end{array}$ \\
\hline Underlying diseases & ML (21), AML (3), MM (2), WM (1) \\
\hline Disease status before auto-HSCT & CR (12), PR (15), non CR (0) \\
\hline Cumulative incidence of neutrophil engraftment & $\begin{array}{l}\text { The median time of engraftment in auto-HSCT was day } 16(11-20) \text {. Cumula- } \\
\text { tive incidence of engraftment (neutrophil) in auto-HSCT was } 1.00\end{array}$ \\
\hline $\begin{array}{l}\text { Severe RRT } \\
\text { (grade } \geq 3 \text { by CTCAE-JCOG) }\end{array}$ & The severe one RRT cases such as TMA (1) \\
\hline OS & 5 year OS: 0.842 (0.633-0.938) with median OS of 1370 days (25-3860) \\
\hline Relapse after auto-HSCT & 3 cases of ML were relapsed after auto-HSCT \\
\hline
\end{tabular}

ML, malignant Iymphoma; AML, acute myeloid leukemia; MM, multiple myeloma; WM, waldenström macroglobulinemia; autoHSCT, autologou hematopoietic stem cell transplantation; CR, complete response; PR, partial response; TMA, thrombotic microangiopathy; OS, overall survival. 
A
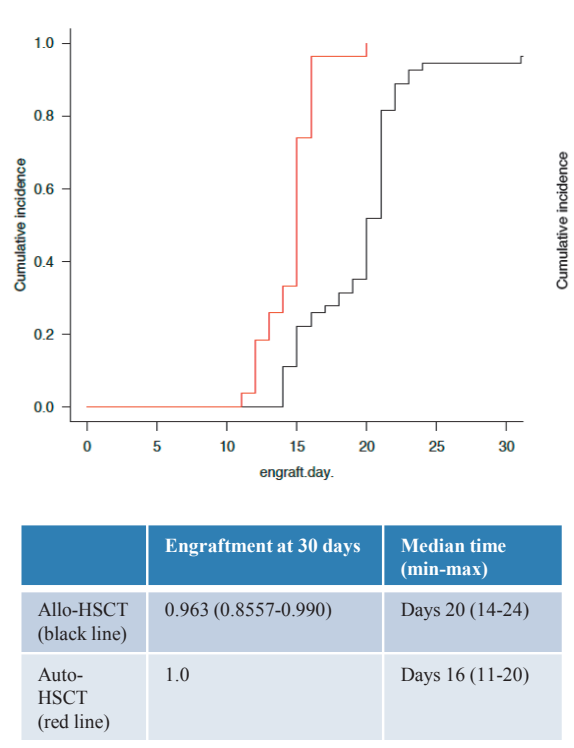

B

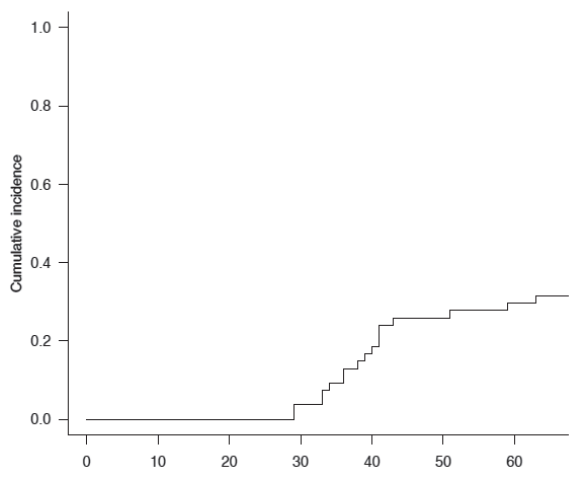

The cumulative incidence of acute GVHD: $0.3148(0.179-0.4281)$ at day 100 in allo-HSCT
$\mathrm{C}$

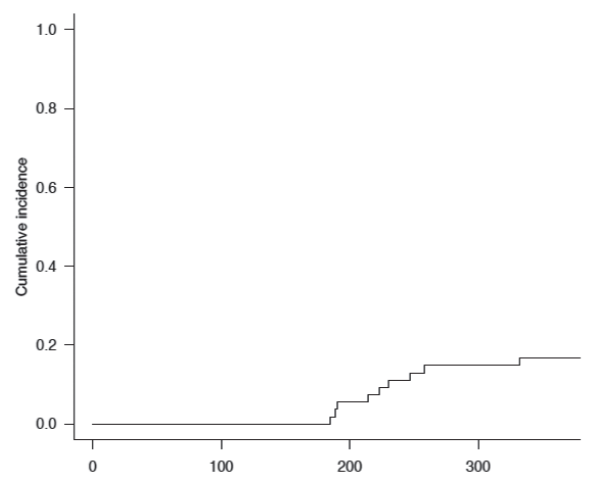

The cumulative incidence of chronic GVHD: $0.1667(0.061-0.2604)$ at 1 year in allo-HSCT

Figure 2. (A) Cumulative incidence of engraftment (neutrophils) in allo-HSCT and auto-HSCT, (B) and (C) Cumulative incidence of acute and chronic GVHD in allo-HSCT

patient), and chronic myeloid leukemia (CML) (one patient). Furthermore, retransplantation was performed for two patients (CML and AML) with engraftment failure (EF) after alloHSCT, and two relapsed AML patients after allo-HSCT, respectively.

The sources of allo-HSCT are described in Table 1A. Among the 54 patients treated with allo-HSCT, the sources of allo-HSCT were mainly sibling BM donors (five donors), sibling PB donors (12 donors), UR-BMT donors from JMDP (25 donors), and CB (12 donors). The numbers of HLA matches and mismatches between recipients and donors were as follows: HLA full-matched donor, 37; HLA-DR one locus mismatched donor: 2; HLA-2 loci mismatched donor: 12; and haploidentical donor: 3 .

The conditioning regimens consisted of MAC (35) and RIC (19) in first transplantation and RIC (4) in second transplantation, as described in the patients and methods section.

The disease statuses of patients with hematological malignancy before allo-HSCT are shown in Table 1. Among 54 patients treated with allo-HSCT, 22, 5, and 27 achieved CR, $\mathrm{PR}$, and non-CR, respectively. The DRI was low in four cases, intermediate in 20 , high in 20 , and very high in eight. However, two patients (with AA) were excluded from DRI assessment.

The median time of engraftment in allo-HSCT was 20 days (14-24) (Figure 2A). The cumulative incidence of engraft- ment (neutrophil) at 30 days in allo-HSCT was 0.963 (0.85570.990) (Figure 2A). The cumulative incidence of acute GVHD was $0.3148(0.179-0.4281)$ at day 100 (Figure 2B). Acute GVHD of grades I - IV occurred in three, 11, two, and one patient, respectively. The cumulative incidence of chronic GVHD was 0.1667 (0.061-0.2604) at one year (Figure 2C).

The OS rate of the 54 allo-HSCT patients was 0.594 (0.441-0.719) at five years, with a median OS of 290 days (19-3,410) (Figure 3). These results were consistent with those in the previous JMDP Bank annual reports.

Severe RRT (grade $\geq 3$ by CTCAE-JCOG) included cardiomyopathy due to CPA (one instance), idiopathic pulmonary syndrome (IPS) (one instance), acute GVHD grades III IV (three instances), acute-exacerbated chronic GVHD (two instances), engraftment failure (two instances), human herpesvirus-6 (HHV-6) encephalitis (two instances), EpsteinBarr virus-associated lymphoproliferative disorders (EBVLPD) (one instance), adenovirus (ADV) infection (one instance), fungal infection (seven instances : Aspergillus infection: 6, mucor infection: 1), subcutaneous mediastinal emphysema (one instance), and chronic persistent HHV-6 viremia and idiopathic necrosis of the femoral head (one instance) (Table 1A). Furthermore, for two patients with engraftment failure after allo-HSCT, retransplantation was performed.

The fungal infections included Aspergillus pneumonia（six 
Figure 3. The OS rate of 54 allo-HSCT patients and 27 auto-HSCT patients

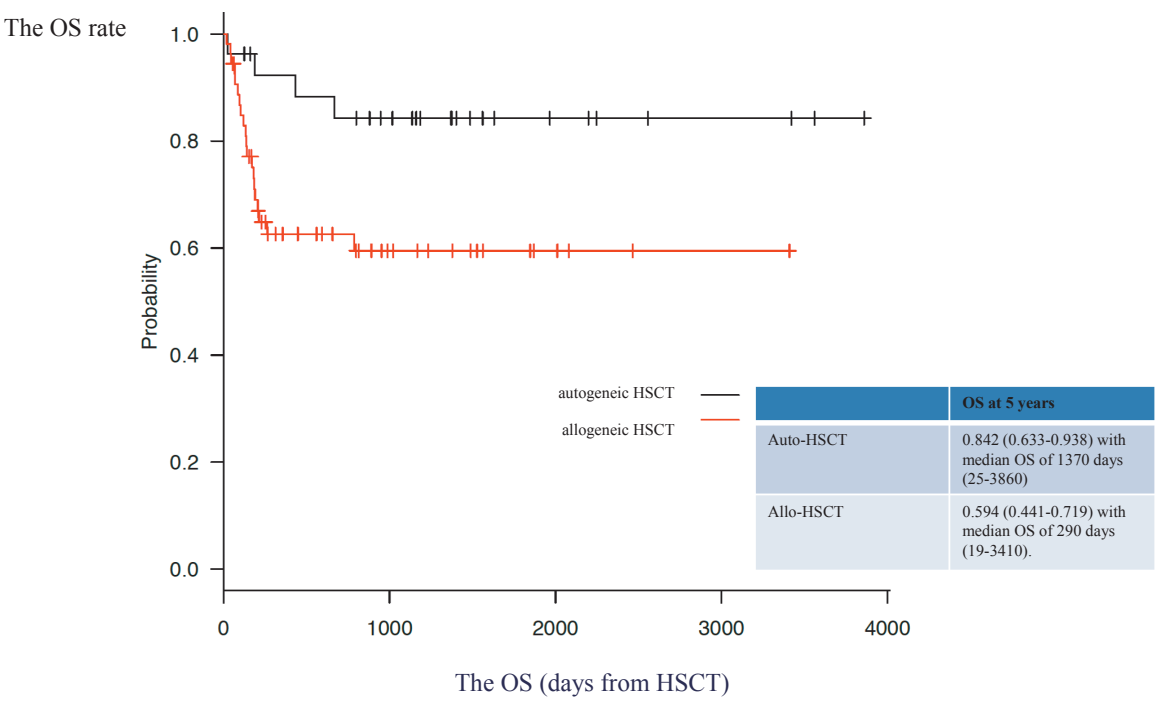

instances) and mucor pneumonia (one instance). The viral infections included HHV-6 infection (eight instances: CBSCT: 6, re-transplantation: 2), BK viral infection (three instances), and ADV infection (one instance). One patient developed EBV-LPD after allo-HSCT by activation of an EBV infection (Table 1A). The majority of patients (44/54) were positive for CMV antigenemia. However, pre-emptive therapy including ganciclovir (DHPG, dihydroxy propoxymethyl guanine) or foscarnet prevented further development of the CMV infection (pneumonia or colitis or other infection sites).

To elucidate the etiology and improve treatment outcomes, we evaluated the detailed characteristics of 20 patients treated with allo-HSCT who subsequently died (Table 2). The causes of death included the progression of relapsed/refractory hematological malignancies (18 patients), HHV-6 encephalitis (one patient), and acute-exacerbated chronic pulmonary GVHD (one patient). Their disease status before allo-HSCT was mostly non-CR $(17 / 20)$. Two patients with AML underwent re-transplantation for relapse after the first allo-HSCT. Notably, six of the 20 patients who died $(30 \%)$ were heavily treated with ventilation (six patients) or hemodialysis (one patient). Although transient disease control was achieved with allo-HSCT $(90 \%: 18 / 20,18 \mathrm{CR}$ and two PD), the remission periods were extremely short, with eventual death at a median OS of 138 days (19-786). Isolated central nervous system (CNS) relapse occurred in four cases of refractory/relapsed hematological malignancy after allo-HSCT. Therefore, the main aim of this study was the identification of the causes of transplantation failure after allo-HSCT. To do so, we statistically analyzed the survival rates for factors such as disease status at transplant ( $\mathrm{CR}$ vs. non-CR), conditioning regimen
(MAC vs. RIC), type of donor source, and DRI (Table 3). Among these markers, DRI $(P<0.001)$ and non-CR status before allo-HSCT $(P<0.001)$ were identified as prognostic factors of OS in univariate analysis (Table 3), consistent with the findings of previous reports. ${ }^{6}$

The OS rate of allo-HSCT according to the disease status (CR, partial remission [PR], and non-CR) is shown in Figure 4. The OS rate of allo-HSCT for CR status before allo-HSCT was 0.85 (0.604-0.949) at five years. The OS rate of alloHSCT for non-CR status before allo-HSCT was 0.276 (0.0940.496) at five years $(P<0.001)$. The OS rate of allo-HSCT according to the DRI (low, intermediate, high, or very high risk) is shown in Figure 5. The OS rate of allo-HSCT on low/ intermediate and high/very high risk before allo-HSCT was $0.85(0.604-0.949)$ and $0.273(0.070-0.532)$ at five years, respectively $(P<0.001)$. The OS rate of allo-HSCT at five years according to the sources of allo-HSCT was as follows: $0.455(0.167-0.707)$ for PB from siblings $(n=12), 0.699$ (0.445-0.853) for UR-BMT donor from the JMPD $(n=25)$, and $0.525(0.150-0.804)$ for a $\mathrm{CB}$ donor $(\mathrm{n}=12)(P=0.446)$. The OS rate of allo-HSCT with RIC and MAC conditioning was $0.638(0.361-0.820)$ and $0.566(0.369-0.723)$ at five years, respectively $(P=0.828)$.

Finally, in areas endemic for human T-lymphotropic virus type 1 (HTLV-1) infection, such as Miyazaki prefecture, we performed allo-HSCT for 10 ATL cases, with an OS of $40 \%$ (Table 4). Severe RRT（grade $\geq 3$ ) included HHV-6 encephalitis in one patient. All six patients with ATL who died developed ATL relapse after allo-HSCT. After the relapse of alloHSCT, only one case (case 10) among the six was treated with mogamulizumab for the relapse. Although mogamulizumab 
Table 2. Characteristics of the 20 allo-HSCT patients who died and four auto-HSCT patients

\begin{tabular}{|c|c|c|c|c|c|c|c|c|c|c|c|}
\hline Sex & age & $\begin{array}{l}\text { Hematological } \\
\text { malignancy }\end{array}$ & Subtype & $\begin{array}{c}\text { Disease } \\
\text { status before } \\
\text { allo-HSCT }\end{array}$ & HSCT & $\begin{array}{c}\text { The } \\
\text { sources } \\
\text { of HSCT }\end{array}$ & $\begin{array}{l}\text { Ventilation or } \\
\text { hemodialysis }\end{array}$ & $\begin{array}{c}\text { Causes of } \\
\text { death }\end{array}$ & $\begin{array}{c}\text { OS } \\
\text { (days) }\end{array}$ & $\begin{array}{l}\text { The days from } \\
\text { initial diatnosis } \\
\text { to allo-HSCT }\end{array}$ & $\begin{array}{c}\text { Chemotherapies } \\
\text { before HSCT } \\
\text { (courses) }\end{array}$ \\
\hline Female & 36 & AML & M2 & non $\mathrm{CR}$ & Allo-HSCT & Sib-PB & - & $\begin{array}{l}\text { Disease } \\
\text { progression }\end{array}$ & 85 & 70 & 2 \\
\hline Female & 37 & AML & M2 & $\mathrm{CR}$ & Allo-HSCT & Sib-PB & - & $\begin{array}{l}\text { Disease } \\
\text { progression }\end{array}$ & 213 & 92 & 3 \\
\hline Female & 53 & AML & M4 & non $\mathrm{CR}$ & Allo-HSCT & Sib-BM & - & $\begin{array}{l}\text { Disease } \\
\text { progression }\end{array}$ & 189 & 76 & 2 \\
\hline Female & 48 & ATL & Acute type & $\mathrm{CR}$ & Allo-HSCT & $\mathrm{CB}$ & Ventilation & $\begin{array}{l}\text { Disease } \\
\text { progression }\end{array}$ & 137 & 98 & 3 \\
\hline Male & 42 & ATL & Acute type & $\mathrm{CR}$ & Allo-HSCT & $\mathrm{CB}$ & - & $\begin{array}{l}\text { Disease } \\
\text { progression }\end{array}$ & 134 & 92 & 3 \\
\hline Female & 34 & ALL & L2, Ph+ & non $\mathrm{CR}$ & Allo-HSCT & Sib BM & $\begin{array}{l}\text { Ventilation and } \\
\text { hemodialysis }\end{array}$ & $\begin{array}{l}\text { Disease } \\
\text { progression }\end{array}$ & 19 & 68 & 2 \\
\hline Male & 45 & $\mathrm{CML}$ & $\mathrm{BC}$ & non $\mathrm{CR}$ & Allo-HSCT & Sib BM & Ventilation & $\begin{array}{c}\text { HHV-6 } \\
\text { encephalitis }\end{array}$ & 96 & 64 & 2 \\
\hline Male & 47 & $\mathrm{ML}$ & $\begin{array}{l}\text { Mantle cell } \\
\text { lymphoma }\end{array}$ & non $\mathrm{CR}$ & Allo-HSCT & UR-BM & - & $\begin{array}{l}\text { Disease } \\
\text { progression }\end{array}$ & 49 & 66 & 2 \\
\hline Male & 35 & AML & M4 & non $\mathrm{CR}$ & Allo-HSCT & UR-BM & Ventilation & $\begin{array}{l}\text { Acute-exacer- } \\
\text { bated chronic } \\
\text { GVHD: lung }\end{array}$ & 263 & 102 & 3 \\
\hline Male & 32 & AML & M2 & non $\mathrm{CR}$ & Allo-HSCT & CB & - & $\begin{array}{l}\text { Disease } \\
\text { progression }\end{array}$ & 206 & 62 & 2 \\
\hline Male & 47 & $M L$ & AITL & non $\mathrm{CR}$ & Allo-HSCT & $\mathrm{CB}$ & - & $\begin{array}{l}\text { Disease } \\
\text { progression }\end{array}$ & 786 & 58 & 2 \\
\hline Male & 62 & ATL & Acute type & non $\mathrm{CR}$ & Allo-HSCT & UR-BM & - & $\begin{array}{l}\text { Disease } \\
\text { progression }\end{array}$ & 67 & 110 & 3 \\
\hline Female & 58 & AML & M2 & non $\mathrm{CR}$ & Allo-HSCT & Sib PB & - & $\begin{array}{l}\text { Disease } \\
\text { progression }\end{array}$ & 102 & 72 & 2 \\
\hline Male & 41 & AML & M3 & non $\mathrm{CR}$ & Allo-HSCT & UR-BM & - & $\begin{array}{l}\text { Disease } \\
\text { progression }\end{array}$ & 180 & 108 & 3 \\
\hline Female & 63 & ATL & Acute type & non $\mathrm{CR}$ & Allo-HSCT & Sib-PB & Ventilation & $\begin{array}{l}\text { Disease } \\
\text { progression }\end{array}$ & 171 & 74 & 2 \\
\hline Female & 59 & ATL & Acute type & non $\mathrm{CR}$ & Allo-HSCT & UR-BM & - & $\begin{array}{l}\text { Disease } \\
\text { progression }\end{array}$ & 139 & 118 & 3 \\
\hline Male & 48 & AML & M2 & non $\mathrm{CR}$ & Allo-HSCT & Sib-PB & - & $\begin{array}{l}\text { Disease } \\
\text { progression }\end{array}$ & 120 & 72 & 2 \\
\hline Male & 57 & $\mathrm{ML}$ & DLBCL & non $\mathrm{CR}$ & Allo-HSCT & UR-BM & - & $\begin{array}{l}\text { Disease } \\
\text { progression }\end{array}$ & 69 & 120 & 3 \\
\hline Female & 57 & ATL & Acute type & non $\mathrm{CR}$ & Allo-HSCT & UR-BM & Ventilation & $\begin{array}{l}\text { Disease } \\
\text { progression }\end{array}$ & 44 & 102 & 3 \\
\hline \multirow[t]{2}{*}{ Male } & 43 & AML & M2 & non $\mathrm{CR}$ & Allo-HSCT & Sib-PB & - & $\begin{array}{l}\text { Disease } \\
\text { progression }\end{array}$ & 185 & 69 & 2 \\
\hline & & & & & & & & & & Median: 75 & 2 \\
\hline Sex & age & $\begin{array}{l}\text { Hematological } \\
\text { malignancy }\end{array}$ & Subtype & $\begin{array}{c}\text { Disease } \\
\text { status before } \\
\text { auto-HSCT }\end{array}$ & HSCT & $\begin{array}{c}\text { The } \\
\text { sources } \\
\text { of HSCT }\end{array}$ & $\begin{array}{l}\text { Ventilation or } \\
\text { hemodialysis }\end{array}$ & $\begin{array}{c}\text { Causes of } \\
\text { death }\end{array}$ & $\begin{array}{c}\text { OS } \\
\text { (days) }\end{array}$ & $\begin{array}{l}\text { The days from } \\
\text { the first relapsed } \\
\text { day to auto-HSCT }\end{array}$ & $\begin{array}{l}\text { Chemotherapies } \\
\text { before HSCT } \\
\text { (courses) }\end{array}$ \\
\hline Male & 55 & $\mathrm{ML}$ & DLBCL & $\mathrm{CR}$ & Auto-HSCT & Auto PB & - & TMA & 187 & 152 & 5 \\
\hline Male & 24 & $\mathrm{ML}$ & DLBCL & PR & Auto-HSCT & Auto PB & - & $\begin{array}{l}\text { Disease } \\
\text { progression }\end{array}$ & 25 & 115 & 5 \\
\hline Female & 60 & $\mathrm{ML}$ & DLBCL & PR & Auto-HSCT & Auto PB & - & $\begin{array}{l}\text { Disease } \\
\text { progression }\end{array}$ & 433 & 120 & 5 \\
\hline \multirow[t]{2}{*}{ Female } & 60 & $\mathrm{ML}$ & DLBCL & PR & Auto-HSCT & Auto PB & - & $\begin{array}{l}\text { Disease } \\
\text { progression }\end{array}$ & 668 & 122 & 5 \\
\hline & & & & & & & & & & Median: 121 & 5 \\
\hline
\end{tabular}

AML, acute myeloid leukemia; ATL, adult T-cell leukemia/lymphoma; ALL, acute lymphoblastic leukemia; CML, chronic myeloid leukemia; ML, malignalt Iymphoma; AITL, Angioimmunoblastic T-Cell Lymphoma; DLBCL, diffuse large B-cell lymphoma; CR, complete response; PR, partial response; autoHSCT, autologous hematopoietic stem cell transplantation; PB, peripheral blood stem cell; BM, Bone marrow; CB, cord blood; HHV-6, human herpes virus-6; TMA, thrombotic microangiopathy; OS, overall survival. 
Table 3. Risk factors affecting poor treatment outcomes in 54 allo-HSCT patients, including 20 who subsequently died

\begin{tabular}{lcrccc}
\hline & Factors & $\mathrm{n}$ & $\begin{array}{c}\text { OS at 5 years } \\
\text { (95\% Confidence interval) }\end{array}$ & $P$-value \\
\hline Conditioning & RIC & 19 & $0.638(0.361-0.820)$ & 0.828 \\
Disease risk index & MAC & 35 & $0.566(0.369-0.723)$ & \\
& Low risk + Intermediate risk & 24 & $0.850(0.604-0.949)$ & $P<0.001$ \\
& High risk+Very high risk & 28 & $0.273(0.070-0.532)$ & \\
Disease status & CR & 22 & $0.850(0.604-0.949)$ & $P<0.001$ \\
& non CR & 27 & $0.276(0.094-0.496)$ & \\
Donor sources & Sibling PB & 12 & $0.455(0.167-0.707)$ & 0.446 \\
& CB & 12 & $0.525(0.150-0.804)$ & \\
& Sibling BM & 5 & $0.400(0.052-0.753)$ & \\
& Unrelated BM & 25 & $0.699(0.445-0.853)$ & \\
\hline
\end{tabular}

RIC, reduced-intensity conditioning; MAC, myeloablative conditioning; OS, overall survival; alloHSCT, allogeneic hematopoietic stem cell transplantation; CR, complete response; PR, partial response; PB, peripheral blood stem cells; $\mathrm{CB}$, cord blood; BM, bone marrow.

Table 4. Characteristics of 10 ATL patients treated with allo-HSCT

\begin{tabular}{|c|c|c|c|c|c|c|c|c|c|c|}
\hline Case & Age & Sex & Subtype & Chemo-therapy & $\begin{array}{l}\text { Disease } \\
\text { status }\end{array}$ & $\begin{array}{l}\text { Allo-HSCT } \\
\text { (Source) }\end{array}$ & $\begin{array}{c}\text { Allo-HSCT } \\
\text { (Conditioning) }\end{array}$ & $\begin{array}{l}\text { GVHD } \\
\text { prophylaxis }\end{array}$ & $\begin{array}{l}\text { Acute } \\
\text { GVHD }\end{array}$ & Survival \\
\hline 1 & 63 & $F$ & Lymphoma & $\begin{array}{c}\mathrm{CHOP}(1)+\mathrm{Mog} \\
(8)\end{array}$ & SD & $\begin{array}{c}\text { Unrelated HLA } \\
\text { full matched } \\
\text { BM }\end{array}$ & $\mathrm{TBI} / \mathrm{CY}$ & CSP+sMTX & $\begin{array}{c}\text { Grade } 2 \\
\text { skin }\end{array}$ & $\begin{array}{l}355 \text { days } \\
(\text { dead })\end{array}$ \\
\hline 2 & 46 & $\mathrm{~F}$ & acute & $\begin{array}{l}\text { VCAP-VMPV- } \\
\text { ECP }(1)+\text { Mog } \\
(4)\end{array}$ & $\mathrm{CR}$ & $\begin{array}{c}\text { Unrelated HLA } \\
\text { full matched } \\
\text { BM }\end{array}$ & $\mathrm{TBI} / \mathrm{CY}$ & $\mathrm{FK}+\mathrm{sMTX}$ & $\begin{array}{l}\text { Grade } 2 \\
\text { skin }\end{array}$ & $\begin{array}{l}295 \text { days } \\
\text { (alive) }\end{array}$ \\
\hline 3 & 54 & M & acute & $\begin{array}{l}\text { VCAP-VMPV- } \\
\text { ECP }(1)+\text { Mog } \\
\text { (8) }\end{array}$ & $\mathrm{CR}$ & $\begin{array}{c}\text { Unrelated HLA } \\
\text { full matched } \\
\text { BM }\end{array}$ & $\mathrm{TBI} / \mathrm{CY}$ & $\mathrm{FK}+\mathrm{sMTX}$ & $\begin{array}{c}\text { Grade } 2 \\
\text { skin }\end{array}$ & $\begin{array}{l}546 \text { days } \\
\text { (alive) }\end{array}$ \\
\hline 4 & 49 & $\mathrm{~F}$ & Lymphoma & CHOP-VMMV & $\mathrm{CR}$ & $\mathrm{CB}$ & $\mathrm{TBI} / \mathrm{CY}$ & CSP+sMTX & - & $\begin{array}{c}138 \text { days } \\
\text { (dead, relapse) }\end{array}$ \\
\hline 5 & 42 & M & Lymphoma & CHOP-VMMV & $\mathrm{CR}$ & $\mathrm{CB}$ & $\mathrm{TBI} / \mathrm{CY}$ & CSP+sMTX & - & $\begin{array}{c}135 \text { days } \\
\text { (dead, relapse) }\end{array}$ \\
\hline 6 & 61 & $\mathrm{~F}$ & acute & CHOP-VMMV & PR & $\mathrm{CB}$ & BU/FLU/TBI & CSP+sMTX & - & $\begin{array}{c}28 \text { days } \\
\text { (dead, relapse) }\end{array}$ \\
\hline 7 & 44 & $F$ & acute & $\begin{array}{c}\text { VCAP-VMPV- } \\
\text { ECP }\end{array}$ & $\mathrm{CR}$ & $\begin{array}{c}\text { Unrelated HLA } \\
\text { full matched } \\
\text { BM }\end{array}$ & $\mathrm{TBI} / \mathrm{CY}$ & $\mathrm{FK}+\mathrm{sMTX}$ & - & $\begin{array}{l}1084 \text { days } \\
\text { (alive) }\end{array}$ \\
\hline 8 & 56 & $\mathrm{~F}$ & acute & $\begin{array}{c}\text { VCAP-VMPV- } \\
\text { ECP }\end{array}$ & $\mathrm{CR}$ & $\begin{array}{c}\text { Unrelated HLA } \\
\text { full matched } \\
\text { BM }\end{array}$ & $\mathrm{TBI} / \mathrm{CY}$ & $\mathrm{FK}+\mathrm{sMTX}$ & - & $\begin{array}{l}1156 \text { days } \\
\text { (alive) }\end{array}$ \\
\hline 9 & 41 & $\mathrm{~F}$ & acute & $\begin{array}{c}\text { VCAP-VMPV- } \\
\text { ECP }\end{array}$ & $\mathrm{CR}$ & $\begin{array}{c}\text { Unrelated HLA } \\
\text { full matched } \\
\text { BM }\end{array}$ & $\mathrm{TBI} / \mathrm{CY}$ & $\mathrm{FK}+\mathrm{sMTX}$ & - & $\begin{array}{l}122 \text { days } \\
\text { (dead) }\end{array}$ \\
\hline 10 & 53 & $\mathrm{~F}$ & acute & $\begin{array}{c}\text { VCAP-VMCP- } \\
\text { ECP (3) }\end{array}$ & PD & UR-BMT & $\begin{array}{c}\mathrm{FLU} / \mathrm{MEL} / \mathrm{Ara} \\
\mathrm{C} / \mathrm{TBI}\end{array}$ & FK+sMTX & - & $\begin{array}{l}225 \text { days } \\
\text { (dead) }\end{array}$ \\
\hline
\end{tabular}

F, female; M, male; allo-HSCT, allogeneic hematopoietic stem cell transplantation; CR, complete response; PR, partial response; TBI, total body irradiation; $\mathrm{CY}$, cyclophosphamide; FLU, Fludarabine; BU, busulfan; $\mathrm{CB}$, cord blood; BM, bone marrow.

was effective against ATL in PB, the progression of the lymph node ( $\mathrm{LN}$ ) lesions led to death at 225 days. The other five cases with relapse were not treated with intensive chemother- apy due to poor PS and activity of daily living (ADL) after allo-HSCT. 
Figure 4. The OS rate of 54 allo-HSCT patients according to the disease status before allo-HSCT
Figure 5. The OS rate of allo-HSCT according to the disease risk index (DRI) (low, intermediate, high, and very high risk)
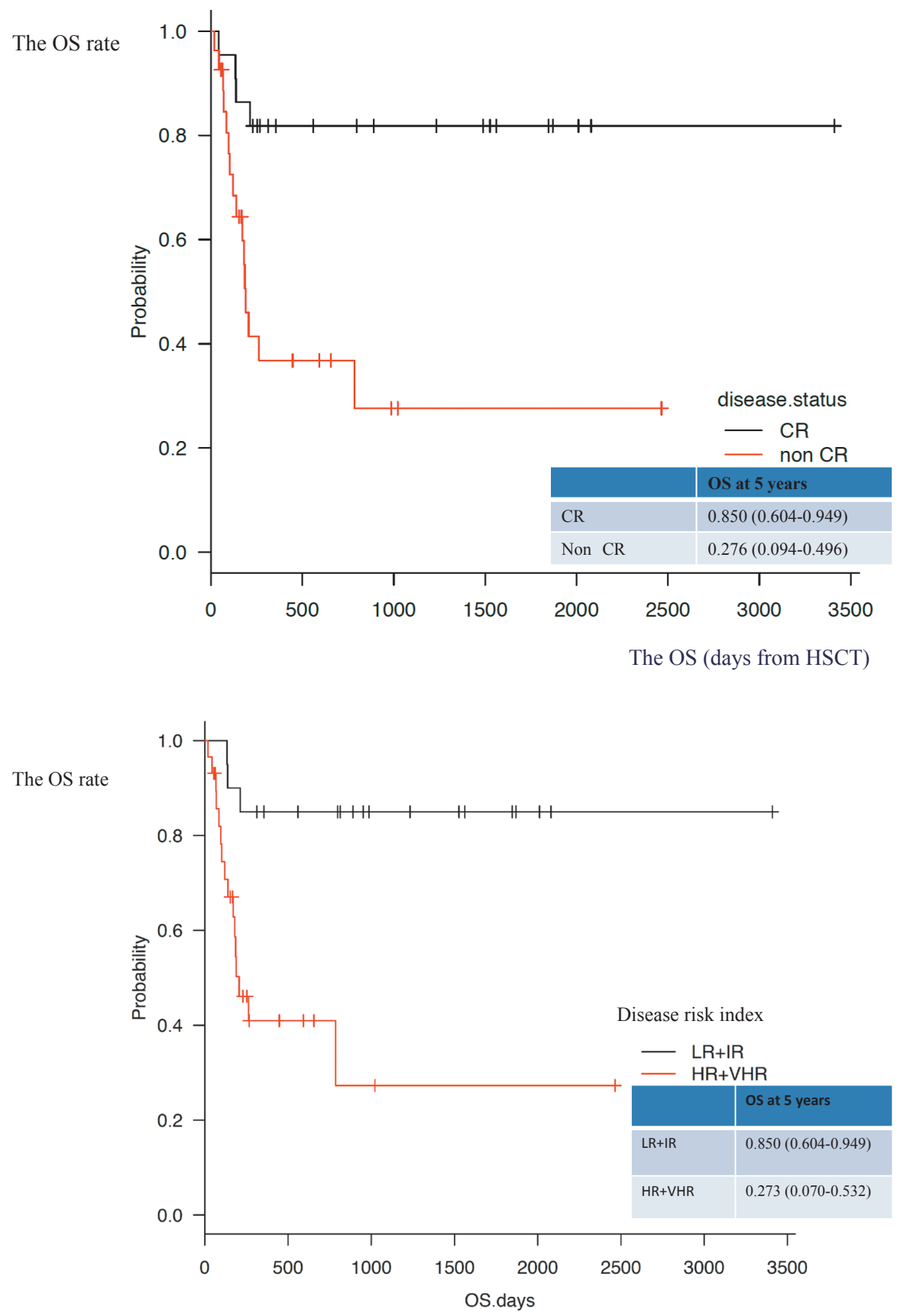

Patient characteristics and treatment outcomes of autoHSCT

The transition of auto-HSCT from January 2006 to December 2016 is shown in Figure 1. The patient characteristics are described in Table 1B. Of the 27 patients, 13 were male and 14 were female. The etiologies of the patients with hematological malignancies are described in Table 1B. Auto-HSCT was performed for ML (21 patients), AML (three patients), MM (two patients), and WM (one patient), indicating that the majority of patients receiving auto-HSCT had ML $(87.5 \% ; 21 / 24)$. The disease statuses of the patients with hematological malignancies before auto-HSCT are shown in Table 1. Among 27 patients treated with auto-HSCT, 12, 15, and 0 achieved a CR, PR, and non-CR, respectively. The median time of engraftment in auto-HSCT was 16 days (1120) (Figure 2A). The cumulative incidence of engraftment (neutrophil) in auto-HSCT was 1.00 (Figure 2A). The OS rate of the 27 auto-HSCT patients was 0.842 (0633-0.938) at five years, with a median OS of 1,370 days (25-3,860) (Figure 3). Severe RRT (grade $\geq 3$ ) occurred as thrombotic microangiopathy (TMA) in one patient.

To elucidate the etiologies and improve treatment out- 
comes, we evaluated the detailed characteristics of the four auto-HSCT patients who subsequently died (Table 2 ). The causes of death included the progression of relapsed/refractory hematological malignancies (three patients) and TMA (one patient). The disease status before auto-HSCT was mostly PR (3/4). Three were due to ML relapse (diffuse large B-cell lymphoma [DLBCL]). Although auto-HSCT transiently achieved disease control (four cases with CR), the remission periods were relatively short, with eventual death at a median of 433 days (25-668). One relapse case was not treated with salvage chemotherapy because of poor PS and ADL after auto-HSCT. Although the other two relapsed cases were treated with salvage chemotherapy, they did not respond to the treatment; therefore, the cases were not treated with allo-HSCT because of the PS and ADL after auto-HSCT.

\section{Discussion}

The results of this retrospective study revealed that the most important issues in our clinical practice was disease progression after allo-HSCT and auto-HSCT. The results also revealed that disease status (non-CR) and DRI (high/very high) at transplantation affected the outcomes of allo-HSCT. Moreover, the occurrence of severe RRT (grade $\geq 3$ ) indicated the need for further improvements in allo-HSCT and autoHSCT. In endemic areas including that in which our institution is located, administration of allo-HSCT is important to improve the poor outcome of ATL.

The current challenges of allo-HSCT and auto-HSCT include ( $\mathrm{i}$ ) non-CR and high/very high DRI of hematological malignancy before allo-HSCT, ( ii ) severe RRT (grade $\geq 3$ ) in allo-HSCT and auto-HSCT, (iii) the role of allo-HSCT for ATL in endemic areas including that in which our institution is located, and iv) relapse after auto-HSCT.

First, regarding allo-HSCT, the results of our study revealed that the major cause of death $(87.5 \% ; 21 / 24)$ was the progression of relapsed or refractory hematological malignancies. Moreover, the univariate analysis revealed that the prognostic factors of OS were DRI $(P<0.001)$ and non-CR status before allo-HSCT $(P<0.001)$, consistent with the findings of previous reports. ${ }^{13,14}$ The OS of non-CR patients with relapsed/refractory hematological malignancies receiving allo-HSCT was consistent with those of previous clinical studies. ${ }^{14}$ In our study, although the conditioning regimen was intensified by the additional administration of HDAC for AML and VP-16 for ALL, consistent with previous reports, 5,14 only transient disease control (19: CR, 3: PR, and 2: PD) was achieved within the extremely short remission periods and eventually death occurred due to relapse at a median of 138 days (19-786). Notably, six of the 24 patients who died $(25 \%)$ were heavily treated with ventilation (six patients) or hemodialysis (one patient), consistent with a previous report. ${ }^{15}$ Thus, non-CR patients tended to present severe RRT during treatment before allo-HSCT and early relapse after allo-HSCT, consistent with previous reports. ${ }^{14,15}$

In the discussion, we have considered and discussed why we did not provide allo-HSCT at the most appropriate timing for some of our patients and what we can do to perform HSCT for these high-risk patients (non-CR high or very high DRI). Among the 20 patients who received allo-HSCT and later died, the median time from the initial diagnosis to alloHSCT was 75 days (58-120), with a median of two courses of chemotherapy (2-3). Among the 20 allo-HSCT patients who died, seven underwent allo-HSCT from JMDP donors because full matched sibling donors or $\mathrm{CB}$ consisting of over $2.0 \times$ $10^{\wedge} 6 / \mathrm{kg}$ total nucleated cells (TNC) were not available. Therefore, these patients required a median of 108 days (66120) from the initial diagnosis to allo-HSCT; thus, haploHSCT may be a future strategic therapeutic option to perform allo-HSCT at an earlier and more appropriate timing than that of allo-HSCT from JMDP donors. Recently, Christopher et al. reported that an immune escape mechanism may be associated with relapse after allo-HSCT due to the dysregulation of pathways that may influence immune function, including down-regulation of major histocompatibility complex (MHC) class II genes involved in antigen presentation. ${ }^{16}$ Thus, novel types of allo-HSCT or additional novel treatment after alloHSCT are essential to prevent early relapse of high-risk relapsed/refractory hematological malignancy treated with allo-HSCT. To date, novel types of allo-HSCT such as HLAhaploidentical HSCT have been broadly attempted to improve the poor outcomes of relapsed/refractory hematological malignancy with non-CR. In Japan, HLA-haploidentical HSCT using post-transplant cyclophosphamide ${ }^{10}$ and HLAhaploidentical HSCT using standard GVHD prophylaxis ${ }^{17}$ showed promising results and fewer adverse effects in phase 3 trials or clinical practice. In our study, HLA-haploidentical HSCT using post-transplant cyclophosphamide was performed for three patients with relapsed/refractory hematological malignancy (MDS, CML BC, and AML). Two of these patients survived with CR (CML and MDS). Thus, HLAhaploidentical HSCT may be a treatment option for relapsed/ 
refractory hematological malignancy with non-CR. Furthermore, new therapeutic agents for ALL, such as anti-CD22 antibody (inotuzumab), ${ }^{18}$ blinatumomab, ${ }^{19}$ and CD19-CAR therapy ; ${ }^{20}$ those for AML, such as azacytidine (AZA) ${ }^{21}$ or FMS-like tyrosine kinase 3 (FLT 3) inhibitors ; ${ }^{22}$ and those for CML, such as tyrosine kinase inhibitors (TKIs) ${ }^{23}$ may be additional novel treatments after allo-HSCT and may serve as alternate therapeutic options to control the disease status of patients with relapsed/refractory hematological malignancy after allo-HSCT in clinical practice.

Second, our results regarding the occurrence of severe RRT (grade $\geq 3$ ) in allo-HSCT and auto-HSCT were consistent with those of previous reports. ${ }^{24}$ Moreover, the three cases of death due to TMA (one case), HHV-6 encephalitis (one case), and chronic pulmonary GVHD were serious complications that require improvement in clinical practice. Newer therapeutic agents such as defibrotide for the treatment of sinusoidal obstruction syndrome (SOS), ${ }^{25}$ letermovir for CMV infection, ${ }^{26}$ prophylactic treatment with foscarnet for HHV-6 infection $^{27}$ and human mesenchymal stem cell (HMSC) for acute $\mathrm{GVHD}^{28}$ have been clinically used in phase 3 trials or clinical practice. Furthermore, reducing RRT following allo-HSCT and auto-HSCT is essential for improving the poor outcomes of allo-HSCT in clinical practice.

Third, in areas endemic for HTLV-1 infection like Miyazaki prefecture, the OS of $40 \%$ after allo-HSCT treatment in 10 ATL cases was consistent with the findings of previous nationwide study ${ }^{29-31}$ and previous endemic area reports from the Kyushu region in Japan. ${ }^{32-35}$ Since the major cause of death after allo-HSCT was ATL relapse $(6 / 6)$, newer therapeutic agents such as $\mathrm{C}-\mathrm{C}$ chemokine receptor type 4 (CCR4) antibody and lenalidomide may be novel treatment options. ${ }^{36,37}$ In the present study, mogamulizumab was effective for the treatment of ATL in PB but was not effective for lymph nodes (LNS) lesions in ATL. Further research is needed to evaluate the efficacy of mogamulizumab and lenalidomide for ATL relapse after allo-HSCT in clinical practice. Additionally, severe RRT included HHV-6 encephalitis in one case. Thus, careful follow-up of severe infections is also necessary in clinical practice.

Finally, disease progression or relapse after auto-HSCT is the most important concern. In our study, three of 21 patients with ML (DLBCL) eventually relapsed after auto-HSCT. Thus, subsequent treatments such as salvage chemotherapy including allo-HSCT should be performed to overcome the poor outcomes after auto-HSCT. The patient showing relapse was not treated with salvage chemotherapy because of the poor PS and ADL after auto-HSCT. Although the other two patients with relapse were treated with salvage chemotherapy, they did not respond to the treatment; hence, they were not treated with allo-HSCT because of their poor PS and ADL after auto-HSCT. To maintain the PS and ADL, additional treatments, including allo-HSCT, should also be performed in clinical practice. In the discussion, we have considered and discussed why we did not provide auto-HSCT at the most appropriate timing for some of our patients and what we can do to perform auto-HSCT for these patients. Among the four auto-HSCT patients who died, the median time from the first relapsed day to auto-HSCT was 121 days (115-152) and a median of five courses of chemotherapy was administered, including one course of PBSCH. Thus, earlier administration of auto-HSCT was required in these patients. Furthermore, because of the early relapse of NHL and poor PS/ADL after auto-HSCT, upfront allo-HSCT may have been a therapeutic option in these deceased patients.

In conclusion, the results of our retrospective study revealed that clinical features, present treatment outcomes, and the critical issues in the non-remission hematological malignancy and high DRI (high/very high) groups before allo-HSCT and severe RRT require improvements in clinical practice. The disease status of non-CR and high DRI (high/ very high) patients before allo-HSCT may significantly affect the treatment outcome of OS treated with allo-HSCT. Among refractory/relapsed non-CR patients, the conditioning regimens, GVHD prophylaxis, and donor sources should be considered when selecting the appropriate treatment options. RRT and other complications following allo-HSCT should be carefully monitored and treated to reduce mortality in clinical practice. Furthermore, relapse after auto-HSCT should be carefully monitored and subsequent treatment including alloHSCT should be considered under sufficient PS and ADL in clinical practice.

\section{Acknowledgments}

We thank the medical staff, including the nurses, laboratory technicians, pharmacists, physical therapists, mental therapists, psychiatrist, and nutritionists, for their excellent care of the patients who were treated with auto-HSCT and allo-HSCT in our institution. 


\section{Authors' contributions}

NK and SY designed the study. NK collected the clinical data. NK and HS analyzed the clinical data. NK wrote the paper. NK, SY, HS, TK, NO, DH, TT, TN, TS, SU, KY, MI, HK, AT, TM, KM, and IK cared for the refractory/relapsed hematological malignancy patients. SM, HO, KS, KN, YM, TM, and KA supervised the refractory/relapsed hematological malignancy patients and the project.

\section{Conflict of interest disclosure}

The authors state that they have no Conflict of Interest (COI).

\section{References}

1. Kurata M, Yanagisawa M, Atsuta Y, et al. Hematopoietic stem cell transplantation in Japan-2013 Nationwide study-Rinsho Ketsueki. 2014; 55: 2381-2399.

2. Ago H. Advances and Perspective in Allogeneic Hematopoietic Cell Transplantation for Elderly Patients. Journal of Hematopoietic Cell Transplantation. 2018; 7: 73-81.

3. Uchida N, Yamamoto H, Taniguchi S. Umbilical cord blood transplantation in adults: An update and future prospects. Journal of Hematopoietic Cell Transplantation. 2013; 2: 1-11.

4. Nakamae H. Current status of HLA haplo-identical transplantation using post-transplantation cyclophosphamide. Journal of Hematopoietic Cell Transplantation. 2019; 8: 16-21.

5. Kondo T. Significance of an intensified myeloablative conditioning regimen for myeloid malignancy and acute lymphoblastic leukemia. Journal of Hematopoietic Cell Transplantation. 2018; 7: 1-8.

6. Maeda Y. Current understanding of the pathophysiology and management of acute graft versus host diseases. Journal of Hematopoietic Cell Transplantation. 2013; 2: 12-24.

7. Nagafuji K, Miyamoto T, Eto T, et al. Monitoring of minimal residual disease (MRD) is useful to predict prognosis of adult patients with Ph-negative ALL: results of a prospective study (ALL MRD2002 Study). J Hematol Oncol. 2013; 6; 6-14.

8. Slavin S, Nagler A, Naparstek E, et al. Nonmyeloablative stem cell transplantation and cell therapy as an alternative to conventional bone marrow transplantation with lethal cytoreduction for the treatment of malignant and nonmalignant hematologic diseases. Blood. 1998; 91: 756-763.

9. Giralt S, Thall PF, Khouri I, et al. Melphalan and purine analogcontaining preparative regimens: reduced-intensity conditioning for patients with hematologic malignancies undergoing allogeneic progenitor cell transplantation. Blood. 2001; 97: 631-637.

10. Sugita J, Kagaya Y, Miyamoto T, et al. Japan Study Group for Cell Therapy and Transplantation (JSCT). Myeloablative and reduced-intensity conditioning in HLA-haploidentical peripheral blood stem cell transplantation using post-transplant cyclophosphamide. Bone Marrow Transplant. 2019; 54: 432441.

11. Kawano N, Yoshida S, Kawano S, et al. The clinical impact of human T-lymphotrophic virus type 1 (HTLV-1) infection on the development of adult T-cell leukemia-lymphoma (ATL) or HTLV-1-associated myelopathy (HAM)/atypical HAM after allogeneic hematopoietic stem cell transplantation (alloHSCT) and renal transplantation. J Clin Exp Hematop. 2018; 58: $107-121$.

12. Cheson BD, Bennett JM, Kopecky KJ, et al. Revised recommendations of the International Working Group for Diagnosis, Standardization of Response Criteria, Treatment Outcomes, and Reporting Standards for Therapeutic Trials in Acute Myeloid Leukemia. J Clin Oncol. 2003; 21: 4642-4649.

13. Armand P, Gibson CJ, Cutler C, et al. A disease risk index for patients undergoing allogeneic stem cell transplantation. Blood. 2012; 120: 905-913.

14. Yoshida S, Henzan H, Ueno T, et al. The Confirmation of Safety for the Intensified Conditioning Regimens: A Retrospective Study of Allogeneic Hematopoietic Stem Cell Transplantation for Non-Remission Hematological Malignant Diseases. Int J Hematol Oncol Stem Cell Res. 2018; 12: 123-131.

15. Nakamura M, Fujii N, Shimizu K, et al. Long-term outcomes in patients treated in the intensive care unit after hematopoietic stem cell transplantation. Int J Hematol. 2018; 108: 622-629.

16. Christopher MJ, Petti AA, Rettig MP, et al. Immune Escape of Relapsed AML cells after allogeneic Transplantation. N Engl J Med. 2018; 379: 2330-2341.

17. Ikegame K, Kaida K, Yoshihara S, et al. Feasibility of unmanipulated haploidentical stem cell transplantation using standard GVHD prophylaxis for HLA-homozygous patients. Int $\mathrm{J}$ Hematol. 2012; 96: 101-108.

18. Kantarjian HM, DeAngelo DJ, Stelljes M, et al. Inotuzumab Ozogamicin versus Standard Therapy for Acute Lymphoblastic Leukemia. N Engl J Med. 2016; 375: 740-753.

19. Kantarjian H, Stein A, Gökbuget N, et al. Blinatumomab versus Chemotherapy for Advanced Acute Lymphoblastic Leukemia. N Engl J Med. 2017; 376: 836-847.

20. Park JH, Rivière I, Gonen M, et al. Long-TermFollow-up of CD19 CAR Therapy in Acute Lymphoblastic Leukemia. N Engl J Med. 2018; 378: 449-459.

21. Schroeder T, Czibere A, Platzbecker U, et al. Azacitidine and donor lymphocyte infusions as first salvage therapy for relapse of AML or MDS after allogeneic stem cell transplantation. Leukemia. 2013; 27: 1229-1235.

22. Usuki K, Sakura T, Kobayashi Y, et al. Clinical profile of gilteritinib in Japanese patients with relapsed/refractory acute myeloid leukemia: An open-label phase 1 study. Cancer Sci. 2018; 109: 3235-3244.

23. Zeidner JF, Zahurak M, Rosner GL, et al. The evolution of treatment strategies for patients with chronic myeloid leukemia 
relapsing after allogeneic bone marrow transplant: can tyrosine kinase inhibitors replace donor lymphocyte infusions? Leuk Lymphoma. 2015; 56: 128-134.

24. Tanaka Y, Kurosawa S, Tajima K, et al. Analysis of non-relapse mortality and causes of death over 15 years following allogeneic hematopoietic stem cell transplantation. Bone Marrow Transplant. 2016; 51: 553-559.

25. Yakushijin K, Ikezoe T, Ohwada C, et al. Clinical effects of recombinant thrombomodulin and defibrotide on sinusoidal obstruction syndrome after allogeneic hematopoietic stem cell transplantation. Bone Marrow Transplant. 2018 Aug 20. doi: 10.1038/s41409-018-0304-4. [Epub ahead of print]

26. Marty FM, Ljungman P, Chemaly RF, et al. Letermovir Prophylaxis for Cytomegalovirus in Hematopoietic-Cell Transplantation. N Engl J Med. 2017; 377: 2433-2444.

27. Ogata M, Takano K, Moriuchi Y, et al. Effects of Prophylactic Foscarnet on Human Herpesvirus-6 Reactivation and Encephalitis in Cord Blood Transplant Recipients: A Prospective Multicenter Trial with an Historical Control Group. Biol Blood Marrow Transplant. 2018; 24: 1264-1273.

28. Hashmi S, Ahmed M, Murad MH, et al. Survival after mesenchymal stromal cell therapy in steroid-refractory acute graftversus-host disease: systematic review and meta-analysis. Lancet Haematol. 2016; 3: 45-52.

29. Hishizawa M, Kanda J, Utsunomiya A, et al. Transplantation of allogeneic hematopoietic stem cells for adult T-cell leukemia: a nationwide retrospective study. Blood. 2010; 116: 1369-1376.

30. Kato K, Uike N, Wake A, et al. ATL Working Group of the Japan Society for Hematopoietic Cell Transplantation. The outcome and characteristics of patients with relapsed adult T-cell leukemia/lymphoma after allogeneic hematopoietic stem cell transplantation. Hematol Oncol. 2019; 37: 54-61.

31. Fujiwara H, Fuji S, Wake A, et al. ATL Working Group of the Japan Society for Hematopoietic Cell Transplantation. Dismal outcome of allogeneic hematopoietic stem cell transplantation for relapsed adult T-cell leukemia/lymphoma, a Japanese nation-wide study. Bone Marrow Transplant. 2017; 52: 484488.

32. Kamiunten A, Sekine M, Kameda T, et al. Outcome of allogeneic hematopoietic cell transplantation in patients with adult $\mathrm{T}$ cell leukemia. Hematol Oncol. 2018; 36: 651-655.

33. Itonaga $\mathrm{H}$, Sawayama Y, Taguchi J, et al. Characteristic patterns of relapse after allogeneic hematopoietic SCT for adult T-cell leukemia-lymphoma: a comparative study of recurrent lesions after transplantation and chemotherapy by the Nagasaki Transplant Group. Bone Marrow Transplant. 2015; 50: 585-591.

34. Kawada H, Yoshimitsu M, Nakamura D, et al. A retrospective analysis of treatment outcomes in adult $\mathrm{T}$ cell leukemia/lymphoma patients with aggressive disease treated with or without allogeneic stemcelltransplantation: A single-center experience. Biol Blood Marrow Transplant. 2015; 21: 696-700.

35. Nakamura T, Oku E, Nomura K, et al. Unrelated cord blood transplantation for patients with adult T-cell leukemia/lymphoma: experience at a single institute. Int J Hematol. 2012; 96: $657-663$.

36. Inoue $\mathrm{Y}$, Endo $\mathrm{S}$, Matsuno N, et al. Safety of mogamulizumab for relapsed ATL after allogeneic hematopoietic cell transplantation. Bone Marrow Transplant. 2019; 54: 338-342.

37. Ishida T, Fujiwara H, Nosaka K, et al. Multicenter Phase II Study of Lenalidomide in Relapsed or Recurrent Adult T-Cell Leukemia/Lymphoma: ATLL-002. J Clin Oncol. 2016; 34: 4086-4093. 